Petra Lazar

Občina Izola

petra.lazar@gmail.com

\title{
Mreženje podjetij s podpornimi institucijami vpliva na inovacijsko uspešnost
}

Inovacije se danes ne razvijajo samo znotraj enega sistema, temveč v sodelovanju z drugimi, pri čemer velja izpostaviti pomen pridobivanja pravih informacij oziroma drugih koristi v čim krajšem času in jih karseda najbolje izkoristiti. V članku predstavljamo pomen sodelovanja, povezovanja oziroma mrežnega obnašanja podjetij s podpornimi institucijami, katerih namen je vzpostavljanje učinkovitega podpornega okolja za podjetja in inovacije. $\mathrm{V}$ prispevku, ki obravnava mala in srednje velika podjetja (MSP), z analizo povezanosti dokažemo pozitivno povezanost podjetij $\mathrm{s}$ podpornimi institucijami $\mathrm{v}$ povezavi $\mathrm{z}$ inovacijsko uspešnostjo.

Ključne besede: mreženje, podjetja, podporne institucije, inovacijska uspešnost

\section{Networking of Companies with Supporting Institutions Affects Innovation Performance}

Today, innovations are not developed by a single system but in collaboration with others. In this regard, it is worth highlighting the importance of obtaining the correct information or other benefits as quickly as possible and making the most of them. This paper presents the importance of cooperation and networking between companies and support institutions to develop an effective support environment for companies and innovations. For the empirical part of the paper, we used linkage analysis to show a positive correlation between companies and support institutions with regard to innovation performance. The paper focused on small and medium-sized enterprises (SMES).

Keywords: networking, companies, support institutions, innovation performance

(cc)BY-SA https://doi.org/10.26493/1854-4231.16.63-67

Mreženje je slovensko poimenovanje, ki se je razvilo iz dobesednega prevoda metaforično motiviranega angleškega poimenovanja networking (Inštitut za slovenski jezik Frana Ramovša 2016) in njegova glavna značilnost predstavlja označevanje razmerja med posamezniki, skupinami in organizacijami. V literaturi se najpogosteje pojavlja delitev mrež na formalne in neformalne. Munih Staničeva $(2003,7)$ pravi, da je formalna mreža sestavljena iz vseh lokalnih in državnih podpornih institucij, bank, zunanjih poslovnih partnerjev z različnih področij, posrednikov in drugih. Neformalno mrežo pa sestavljajo družinski člani, prijatelji, sorodniki. Glede na različne vsebine izmenjavanj znotraj mrež sta Bratkovičeva in Antončič $(2008,85)$ mreže razdelila na (a) mreže za pridobivanje virov (finančnih, materialnih in človeških), (b) mreže za pridobivanje informacij in nasvetov ter (c) mreže prijateljev (psihološka in moralna podpora). Osnovni namen mreženja pa je ves čas enak, to je pridobivati informacije in druge koristi ter jih karseda najbolje implementirati. Pomembno je, da podjetja izboljšujejo svojo bazo znanja s ključnimi partnerji, s katerimi sodelujejo, raznolikosti omrežja ter kontinuiran način sodelovanja pa jih vodijo do uspešnosti in razvoja konkurenčne prednosti (Nieto in Santamaria 2007).

Dosedanje raziskave so pokazale, da imajo podjetja, ki vzdržujejo tesne odnose s kupci, z dobavitelji, raziskovalnimi ustanovami in s konkurenti, več možnosti za uspeh pri inovacijah izdelkov in storitev (Ritter in Gemünden 2003). Ritter in Gemünden (2004, 548-556) sta v svoji raziskavi 
zapisala, da sta za inovacijski uspeh podjetja še posebej pomembni sposobnost razvijanja in uporaba tehnološko usmerjenih medorganizacijskih odnosov. Raziskave s področja podpornih institucij kažejo na to, da vlade $\mathrm{z}$ različnimi programi spodbujajo razvoj inovacij v podjetjih. Primer kanadske vlade prikazuje, da se $\mathrm{z}$ novimi strateškimi in političnimi strategijami osredotočajo na razvoj močnejših vezi med univerzami in podjetji, vse z namenom razvoja inovacij (Godin in Gingras 2000 po Zeng, Xie in Tam 2010). Ameriška raziskava je na področju MSP potrdila pomembnost povezav med podpornimi institucijami in uspešnostjo inovacij v MSP (Biggs in Shah 2006). Študija Evropske komisije (European Commission $2011,8)$ je pokazala, da so se pri uporabi javnih podpornih programov (finančnih in nefinančnih) na nacionalni ravni in ravni Evropske unije prihodki MSP na ciljnem trgu v povprečju povečali za $28 \%$, skupni prihodki podjetij za $11 \%$, ustvarili ali ohranili so tri delovna mesta ter prispevali $\mathrm{k}$ približno $12 \%$ prihodkov v naslednjem letu.

\section{Razlogi za mrežno obnašanje podjetij}

Podjetniško sodelovanje v mrežah med drugim prinaša nižje stroške, povečuje učinkovitost in uspešnost poslovanja, inovativen pristop reševanja problemov ter dostop do specializiranih informacij, novih tehnologij in prenosa znanja (Bratkovič in Antončič 2008, 87-88). Z dolgotrajnim in intenzivnim načinom delovanja $\mathrm{v}$ mrežah podjetja dostopajo do redkih virov, informacij, tehnologij in trgov ter povečujejo razvoj konkurenčne prednosti na domačih in tujih trgih (Buckley 1993; Hitt idr. 2001 po Ruzzier in Konečnik Ruzzier 2007, 43). V različnih študijah je mreženje predstavljeno tudi kot vir idej in zbiranja informacij za prepoznavanje podjetniške priložnosti (Birley 1985; Smeltzer, Van Hook in Hutt 1991; Singh idr. 1999; Hoang in Young 2000).

Ključni razlogi se kažejo predvsem v izboljšanem dostopu do informacij, znanja, sposobnosti, hitrejši izmenjavi znanja, učenja in izkušenj med udeleženci, intenzivnejše povezave predstavljajo sinergijo med udeleženci, razvijata se večja odzivnost in sposobnost prilagajanja spremembam na tehnološkem in organizacijskem področju, zmanjšujejo se tveganje, informacijski in transakcijski stroški ter vzpostavljajo boljši pogoji za zaupanje, ki različnim akterjem omogočajo sočasno tekmovanje in konkuriranje (Harrison 1992, 478 po Hotz-Hart 2000, 433).

Vsi našteti razlogi predstavljajo potencialne priložnosti, ki jih morajo udeleženci v procesu mreženja znati tudi uspešno izkoristiti. V nasprotnem primeru lahko te mreže tudi negativno vplivajo na inovacijsko dejavnost.

\section{Mreženje podjetij s podpornimi institucijami}

Zaradi specifičnih ekonomskih značilnosti in tehnologije se mora danes $\mathrm{v}$ spodbujanje razvoja konkurence vključiti tudi država. Ne gre samo za vlaganja $\mathrm{v}$ raziskave in razvoj, temveč tudi za razvoj podpornih in znanstvenih institucij, ki predstavljajo intelektualno infrastrukturo, spodbujati mora izobraževanje, ustvarjati pogoje za razvoj podjetništva in zagotavljati kakovostno okolje (Konda 2014). Na podlagi različnih vladnih programov in politik, izobraževanj, usposabljanj, z razvojem infrastrukture in s finančno pomočjo želijo te institucije ustvariti inovacijam prijazno okolje. Načini, s katerimi vladna politika spodbuja razvoj, so: finančna politika, industrijska politika, zaščita intelektualne lastnine itn. ter $z$ njimi povezani regulativni ukrepi oziroma strateški programi, ki vključujejo znanstvene in tehnične projekte, izgradnja inovacijskih platform ter javna podpora, ki vključuje državno subvencijo, subvencije za raziskave in razvoj ter inovacijske dejavnosti. K temu spada še sodelovanje $z$ vladnimi agencijami, kjer vlada financira razne sporazume (Zeng, Xie in Tam 2010).

V Sloveniji so ukrepi za spodbujanje podjetništva in organiziranost ter postopki za dodeljevanje sredstev, namenjenih oblikovanju podpornega okolja za podjetništvo, opredeljeni v Zakonu o podpornem okolju za podjetništvo ( $v$ nadaljevanju ZPOP-1) (2007).

Institucije, ki so odgovorne za izvajanje, predstavljajo podjetja, izobraževalne organizacije, raziskovalni inštituti, organizacije za prenos tehnologije, gospodarske zbornice, interesna združenja, inovatorski centri, tehnološki parki in državne institucije (ministrstva, agencije) (Kavaš 1998 po Konda 2014).

\section{Namen in analiza raziskave}

Namen raziskave je dokazati, da je mreženje $s$ podpornimi institucijami povezano $\mathrm{z}$ inovacijsko uspešnostjo v MSP, da se podjetja povezujejo oziroma mrežno obnašajo s podpornimi institucijami ter da je rezultat teh povezav inovacijska uspešnost podjetij. V okviru raziskave smo postavili naslednjo hipotezo:

H1 Mreženje med MSP in podpornimi institucijami je pozitivno povezano $z$ inovacijsko uspešnostjo $v$ MSP. 
Za pridobivanje primarnih podatkov smo se na osnovi preučevane populacije in potrebe po dovolj velikem vzorcu odločili za spletni anketni vprašalnik, ki je bil sestavljen iz vprašanj iz že obstoječe literature. Vprašanja so bila zaprtega tipa, pri čemer smo uporabili Likertovo lestvico od 1 do 5, kjer so anketiranci obkrožili tisto številko, ki najbolje odraža njihovo stališče.

Pridobljene podatke smo analizirali s pomočjo statističnega programa SPSS. Pri inferenčni statistiki smo za potrditev ali zavrnitev postavljene hipoteze uporabili Pearsonov koeficient korelacije, s katerim smo preverjali povezanost med izbranimi spremenljivkami.

Obseg sodelovanja s podpornimi institucijami smo merili s sedmimi trditvami, inovativnost pa s skupno enaindvajsetimi trditvami, pri čemer smo inovativnost razdelili na štiri področja: inovacijsko uspešnost izdelkov in storitev, procesov, trženjske in organizacijske inovacije. Inovacije so v raziskavi predstavljene in obravnavane kot (Benavente, Soumitra in Wunsch-Vincent 2012, 5) implementacija novega ali bistveno izboljšanega produkta (izdelka ali storitve), novega procesa, nove tržne metode, nove organizacijske metode ali novega načina organizacije dela, ki v raziskavi predstavljajo inovacijsko uspešnost podjetja.

S pomočjo AJPES-a (https://www.ajpes.si) smo pridobili podatke o vseh MSP na območju Republike Slovenije. Za nas so bili najpomembnejši elektronski naslovi, na katere smo, v času od 26. junija do 26. septembra 2020, skupno razposlali 3.392 e-sporočil, ki so vsebovala spremni dopis in dostop do anketnega vprašalnika. Skupno je $\mathrm{v}$ raziskavi sodelovalo 441 anketirancev, od katerih jih je 160 anketni vprašalnik izpolnilo v celoti, 67 pa delno. Skupno število ustrezno izpolnjenih anketnih vprašalnikov je 227.

$\mathrm{V}$ anketni raziskavi je sodelovalo kar $80,6 \%$ podjetnikov iz družbe $z$ omejeno odgovornostjo (d.o.o.), 9,3\% samostojnih podjetnikov (s.p.), $4 \%$ podjetnikov iz delniške družbe (d. d.), 2,2 \% podjetnikov iz družbe $z$ neomejeno odgovornostjo (d. n. o.), o,4\% društev ter 3,5\% drugih (zadruga, zavod, gospodarsko interesno združenje). Gre za $44,9 \%$ anketirancev iz malih podjetij (od 11 do 50 zaposlenih), 34,8\% iz mikropodjetij (od o do 10 zaposlenih) ter $20,3 \%$ iz srednje velikih podjetij (od 51 do 250 zaposlenih). Največji delež $(69,6 \%)$ podjetij je starih več kot 20 let, z 19,8\% sledijo podjetja, stara med 11 in 20 let, nato s $5,7 \%$ podjetja, stara med 6 in 10 let, z 3,1\% tista od o do 2 leti in na zadnjem mestu z 1,8\% podjetja, stara od 3 do 5 let. Glede na glavno dejavnost podje- tja 51,9\% anketiranih prihaja iz storitvene dejavnosti, $25 \%$ iz proizvodnje dejavnosti in $23,1 \%$ iz trgovske dejavnosti.

\section{Opisna statistika}

Anketiranci se v povprečju niso strinjali s trditvami sklopa obsega sodelovanja s podpornimi institucijami. Še nekako najbolj so se nagibali k niti strinjanju niti nestrinjanju s tem, da so sodelovali s podpornimi institucijami za informacijske storitve $(\bar{x}=2,78, \sigma=1,397)$ ter da podporne institucije pogosto organizirajo sejme in prireditve, na katerih se podjetniki srečujejo in vzpostavljajo stike $(\bar{x}=2,77, \sigma=1,299)$. Anketiranci se niso strinjali s trditvami, da so sodelovali s podpornimi institucijami za inovacijske storitve $(\bar{x}=2,45, \sigma$ $=1,334)$, da so sodelovali s podpornimi institucijami za nadzor storitev ( $\bar{x}=2,35, \sigma=1,200$ ) ter da vladna politika spodbuja in podpira sodelovanje med podjetji $(\bar{x}=2,33, \sigma=1,023)$. Najmanj pa so se strinjali s trditvama, da so prejeli državno subvencijo za vzpodbujanje inovativnosti $(\bar{x}=1,61, \sigma$ $=1,110$ ) ter da so sodelovali $\mathrm{z}$ gospodarsko zbornico pri razvoju inovacije $(\bar{x}=1,72, \sigma=1,141)$.

Mreženje med malimi in srednje velikimi podjetji ter podpornimi institucijami inovacijska uspešnost

V preglednici 1 je prikazana korelacijska matrika linearne povezanosti spremenljivk mreženja med podpornimi institucijami in inovacijske uspešnosti z njenimi poddimenzijami.

Kot lahko razberemo iz Pearsonovega koeficienta korelacije, obstaja statistično značilna srednje močna pozitivna povezanost med sodelovanjem $s$ podpornimi institucijami in inovacijsko uspešnostjo ( $p=0,000<0,01, R=0,483$ ). Vsebinsko to pomeni, da je mreženje med MSP in podpornimi institucijami srednje močno pozitivno povezano $z$ inovacijsko uspešnostjo, nadalje, $z$ večanjem sodelovanja s podpornimi institucijami se veča tudi strinjanje s trditvami iz sklopa inovacijske uspešnosti.

Pri sklopu sodelovanja s podpornimi institucijami ter produktnimi in storitvenimi inovacijami obstaja statistično značilna šibka pozitivna povezanost ( $p=0,000<0,01, R=0,337$ ). Enako velja med sklopom sodelovanja s podpornimi institucijami in procesnimi inovacijami $(p=0,000<0,01$, $R=0,379)$ ter med sklopom sodelovanja s podpornimi institucijami in marketinškimi inovacijami ( $p=0,000<0,01, R=0,356$ ). Med sklopom sodelovanja s podpornimi institucijami in organizacijskimi inovacijami pa obstaja statistično značilna 
Preglednica 1 Korelacijska metrika - mreženje med malimi in srednje velikimi podjetji ter podpornimi institucijami (inovacijska uspešnost)

\begin{tabular}{llr}
\hline Inovacijska uspešnost & Pearsonov koeficient korelacije & $0,483^{* *}$ \\
& $p$ (dvostranska) & 0,000 \\
& $N$ & 142 \\
\hline Produktne in storitvene inovacije & Pearsonov koeficient korelacije & $0,337^{* *}$ \\
& $p$ (dvostranska) & 0,000 \\
& $N$ & 159 \\
\hline Procesne inovacije & Pearsonov koeficient korelacije & $0,379^{* *}$ \\
& $p$ (dvostranska) & 0,000 \\
Marketinške inovacije & $N$ & 151 \\
\hline Organizacijske inovacije & Pearsonov koeficient korelacije & $0,356^{* *}$ \\
& $p$ (dvostranska) & 0,000 \\
& $N$ & 153 \\
\hline Opombe ** Korelacija je statistično značilna ob stopnji značilnosti o,o1 (dvostranska). & $0,480^{* *}$
\end{tabular}

srednje močna pozitivna povezanost ( $p=0,000$ $<0,01, R=0,480)$. Vsi navedeni rezultati nakazujejo, da se z večanjem strinjanja s trditvami sklopa sodelovanja s podpornimi institucijami veča tudi strinjanje s trditvami vseh podsklopov inovacij (produktnih in storitvenih, procesnih, marketinških in organizacijskih).

Na osnovi navedenega hipoteze H1, "Mreženje med MSP in podporni institucijami je pozitivno povezano $z$ inovacijsko uspešnostjo v MSP«, ne ovržemo, saj obstaja šibka do srednje močna pozitivna povezanost.

\section{Sklep}

Tako kot mnoge predhodne raziskave smo tudi sami dokazali, da je mreženje med MSP in podpornimi institucijami pozitivno povezano $\mathrm{z}$ inovacijsko uspešnostjo, ki smo jo obravnavali kot produktno, storitveno, procesno, trženjsko in organizacijsko inovacijo.

Dokazali smo, da mreženje podjetij s podpornimi institucijami vpliva na inovacijsko uspešnost, so se pa te povezave izkazale kot šibke oziroma manj intenzivne. Anketiranci so se še najbolj nagibali $\mathrm{k}$ sodelovanju s podpornimi institucijami za informacijske storitve in $\mathrm{k}$ temu, da podporne institucije pogosto organizirajo sejme in prireditve, na katerih se podjetniki lahko srečujejo ter vzpostavljajo stike. Kljub temu da je naloga Ministrstva za gospodarski razvoj in tehnologijo ter Javne agencije za področje investicij, tehnološkega razvoja, podjetništva in internacionalizacije spodbujanje podjetništva in zagotavljanje učinkovitega podjetniškega okolja, se anketiranci niso strinjali s trditvijo, da vladna politika spodbuja in podpira sodelovanje med podjetji. Analizirani podatki prikazujejo še nestrinjanje anketirancev o sodelovanju $\mathrm{z}$ gospodarsko zbornico pri razvoju inovacije in o prejemu državne subvencije za vzpodbujanje inovativnosti. Glede na rezultate smo ugotovili še, da se podjetniki najbolj nagibajo k inovacijski uspešnosti izdelkov in storitev, pri čemer so se najbolj strinjali s trditvijo, da je njihovo podjetje konstanto iskalo možnosti za nove storitve. Sledijo inovacijska uspešnost procesov, trženjske inovacije in kot zadnje organizacijske inovacije, ki so bile deležne največjega deleža nestrinjanja.

$Z$ rezultati kvantitativne raziskave smo potrdili, da je potreba po mreženju s podpornimi institucijami prisotna in vpliva na inovacijsko uspešnost podjetja. Zapišemo lahko, da mreženje danes predstavlja orodje za ustvarjanje novih priložnosti, pri čemer je ključno zavedanje, da je za dolgoročni razvoj podjetja pomemben vsak gradnik. Glede na ugotovljeno predlagamo dodatna vlaganja v razvoj in izkoriščanje mrež, bodisi skozi dodatna izobraževanja, sodelovanja $\mathrm{z}$ okoljem, vlaganje v zaupanje med zaposlene in okolico, predvsem pa učenje, kako prepoznati obstoječe in potencialne mreže. Menimo namreč, da sta za šibke vezi na področju mreženja s podpornimi institu- 
cijami kriva predvsem primanjkovanje znanja in usposobljenosti ter nepoznavanje sistema s spremljajočo zapleteno birokracijo.

\section{Literatura}

Benavente, D., D. Soumitra in S. Wunsch-Vincent. 2012. »The Global Innovation Index 2012: Stronger Innovation Linkages for Global Growth."V The Global Innovation Index 2012: Stronger Innovation Linkages for Global Growth, ur. D. Soumitra, 3-80. Fontainebleau: INSEAD.

Biggs, T., in M. K. Shah. 2006. "African SMEs, Networks, and Manufacturing Performance. « Journal of Banking and Finance 30 (11): 3043-3066.

Birley, S. 1985. "The Role of Networks in the Entrereneruial Process. « Journal of Business Venturing 1 (1): 107-117.

Bratkovič, T., in B. Antončič. 2008. »Podjetniške mreže.» V Podjetništvo, ur. M. Ruzzier, B. Antončič, T. Bratkovič in R. Hisrich, 81-92. Koper: Društvo za akademske in aplikativne raziskave.

Buckley, P. J. 1993. »Foreign Direct Investment by Small and Medium Sized Enterprises: The Theoretical Background. "V The Internationalization of the Firm: A Reader, ur. P. J. Buckley in P. N. Ghauri, 89-100. London: Academic Press.

European Commission. 2011. Opportunities for the Internationalisation of European SMES: Final Report. Bruselj: European Commission.

Godin, B., in Y. Gingras. 2000. »The Place of Universities in the Knowledge Production. "Research Policy 29 (2): 273-275.

Harrison, B. 1992. »Industrial Districts: Old Wine in New Bottles?« Regional Studies 26 (5): 469-483.

Hitt, M. A., R. D. Ireland, S. M. Camp in D. L. Sexton. 2001. "Guest Editors' Introduction to the Special Issue Strategic Entrepreneurship: Entrepreneurial Strategies for Wealth Creation.« Strategic Management Journal 22 (6-7): 479-491.

Hoang, H., in N. Young. 2000. Social Embeddedness and Entrepreneurial Opportunity Recognition: (More) Evidence of Embeddedness. Wellesley, MA: Babson College.

Hotz-Hart, B. 200o. "Innovation Networks, Regions and Globalization." V The Oxford Handbook of Economic Geography, ur. G. L. Clark, M. P. Feldman in M. S. Gertler, 432-450. New York: Oxford University Press.
Inštitut za slovenski jezik Frana Ramovša. 2016. »Mreženje.« Terminološka svetovalnica. https://isjfr.zrc -sazu.si/sl/terminologisce/svetovanje/mrezenje\#v.

Kavaš, D. 1998. Slovenski nacionalni inovacijski sistem v primerjavi z nacionalnimi inovacijskimi sistemi $v$ izbranih državah Evropske unije. Ljubljana: Ekonomska fakulteta.

Konda, I. 2014. »Unija inovacij in inovacijska dejavnost Slovenije.«Revija za ekonomske in poslovne vede 1 (1): 38-50.

Munih Stanič, Š. 2003. »Medorganizacijske in medpodjetniške mreže: pregled in smernice za nadaljnje raziskave.« Magistrsko delo, Univerza v Ljubljani.

Nieto, M. J., in L. Santamaria. 2007. »The Importance of Diverse Collaborative Networks for the Novelty of Product Innovation. "Technovation 27 (6-7): 367377.

Ritter, T., in H. G. Gemünden. 2003. »Network Competence its Impact on Innovation Success and Its Antecedents. « Journal of Business Research 56 (9): 745755 .

Ritter, T., in H. G. Gemünden. 2004. "The Impact of a Company's Business Strategy on Its Technological Competence, Network Competence and Innovation Success. " Journal of Business Research 57 (5): 544556.

Ruzzier, M., in M. Konečnik Ruzzier. 2007. „Internacionalizacija malih in srednjih podjetij: integrativni konceptualni model.« Organizacija 40 (1): 42-53.

Singh, R. P., G. E. Hills, G. T. Lumpkin in R. C. Hybels. 1999. The Entrepreneurial Opportunity Recognition Process: Examining the Role of Self-Perceived Alertness and Social Networks. Chicago: Academy of Management.

Smeltzer, L. R., B. L. Van Hook, R. W. Hutt. 1991. "Analysis and Use of Advisors as Information Sources in Venture Startups. "Journal of Small Business Management 29 (3): 10-20.

Zakon o podpornem okolju za podjetništvo (ZPOP-1). 2007. Uradni list Republike Slovenije, št. 102. https:// www.uradni-list.si/1/objava.jsp?sop=2007-01 -5064 .

Zeng, X. S., M. X. Xie in M. C. Tam. 2010. "Relationship between Cooperation Networks and Innovation Performance of SMES."Technovation 30 (3): 181-194. 